Research Article

\title{
Model Predictive Control on Constant Voltage Output of a Proton Exchange Membrane Fuel Cell
}

\author{
Liping Fan ${ }^{1, *}$, Jun Zhang ${ }^{2}$ and Chong $\mathbf{L i}^{2}$ \\ ${ }^{1}$ College of Environment and Safety Engineering, Shenyang University of Chemical Technology, Shenyang, 110142- China \\ ${ }^{2}$ College of Information Engineering, Shenyang University of Chemical Technology, Shenyang 110142- China
}

Received 15 May 2013; Accepted 25 July 2013

\begin{abstract}
As one of the promising renewable energy sources, the proton exchange membrane fuel cell (PEMFC) has received more and more attentions in recent years. Performance improvement is necessary for popularization and application of PEMFC. A model predictive controller based on the receding horizon control approach is designed for the PEMFC. Hydrogen pressure and oxygen pressure are chosen as the control variables respectively, and the main control objective is to keep the output voltage constant. Simulation results show that the designed MPC controller can give a satisfactory control effect.
\end{abstract}

Keywords: PEMFC, receding horizon control, model predictive controller, simulation

\section{Introduction}

With the increasingly serious energy crisis and deteriorating environmental conditions, new energy sources with low pollution and high conversion efficiency are needed to develop. Fuel cells are promising energy sources that produce electrical currents with almost null pollutant emissions [1]. The proton exchange membrane fuel cell (PEMFC), as a kind of power generating device, has been attached importance by all governments and enterprises in the world. PEMFC can convert chemical energy in hydrogen and oxygen directly to electric energy cleanly and efficiently [2], [3]. PEMFC can be used as emergency power supply and small mobile power supply for outdoors power supply, emergency power supply and high reliable and high stable power supply [4]. On the other hand, it also can be used as the power of new generation vehicle owing to its low working temperature, quick starting speed, high power density (small volume). Besides, on the contrast of centralized power supply, PEMFC can be considered as distribution power supply and be gridded into power supply system for peak modulation [5], [6].

The performance of PEMFC, being important and getting more and more attention in recent years, is known to be influenced by many parameters such as operating temperatures both fuel cell and humidifiers, pressure, flow rates and relative humidity of fuel and oxidant gases [7]. Maintaining a fuel cell system in correct operating conditions requires good system control. Model predictive control (MPC) is an optimization strategy for the control of constrained dynamic systems [8]. MPC uses multi-step

\footnotetext{
*E-mail address: flpsd@163.com

ISSN: 1791-2377 @ 2013 Kavala Institute of Technology. All rights reserved.
}

prediction, rolling optimization and feedback correction control strategies [9], so it can not only give a good control effect and strong robustness, but also have an advantage of less demand on the accuracy of the model. It is an effective method to solve complex industrial process control [10], [11].

In this paper, a simulation platform for fuel cell was set up based on a single fuel cell model with hydrogen pressure and oxygen pressure as input variables and voltage as output variable. A model predictive controller (MPC) is designed according to the Receding Horizon Control (RHC) approach. This paper is organized as follows. The mathematical model for a typical proton exchange membrane fuel cell is described in Section 2. Section 3 presents a brief description of designing a MPC controller for PEMFC. Simulation results are presented in section 4 to confirm the effectiveness and the applicability of the proposed method.

\section{Mathematical Model of PEMFC}

Mathematical models and simulation are needed as tools in optimization of fuel cells. In system studies, it is important to have an adequate model to estimate overall performance of a PEM fuel cell in terms of operating conditions without extensive calculations [12].

PEM fuel cell electrochemical process starts on the anode side where $\mathrm{H}_{2}$ molecules are brought by flow plate channels. Anode catalyst divides hydrogen on protons $\mathrm{H}^{+}$ that travel to cathode through membrane and electrons $\mathrm{e}^{-}$that travel to cathode over external electrical circuit. At the cathode hydrogen protons $\mathrm{H}^{+}$and electrons $\mathrm{e}^{-}$combine with oxygen $\mathrm{O}_{2}$ by use of catalyst, to form water $\mathrm{H}_{2} \mathrm{O}$ and heat. Described reactions can be expressed by the following equations [13], [14], [15]: 


$$
\begin{aligned}
& \mathrm{H}_{2} \rightarrow 2 \mathrm{H}^{+}+2 \mathrm{e}^{-} \quad \text { (Anode) } \\
& \frac{1}{2} \mathrm{O}_{2}+\mathrm{H}^{+}+2 \mathrm{e}^{-} \rightarrow \mathrm{H}_{2} \mathrm{O} \quad \text { (Cathode) }
\end{aligned}
$$

The thermodynamic potential of the cell representing its reversible voltage can be represented by the following formula

$$
E_{\text {nernst }}=\frac{\Delta G}{2 F}+\frac{\Delta S}{2 F}\left(T-T_{\text {ref }}\right)+\frac{R T}{2 F}\left[\ln \left(P_{\mathrm{H} 2}\right)+\frac{1}{2} \ln \left(P_{\mathrm{O} 2}\right)\right]
$$

where, $\Delta G$ is Gibbs free energy, $F$ is Faraday constant, $\Delta S$ is Entropy change, $R$ is Universal gas constant, $P_{\mathrm{H} 2}$ and $P_{\mathrm{O} 2}$ are respectively the pressure of $\mathrm{H}_{2}$ and $\mathrm{O}_{2}, T$ is the ambient temperature, and $T_{\text {ref }}$ is the reference temperature. Empirical formula for fuel cell voltage is

$V_{\text {fc }}=E_{\text {nernst }}-V_{\text {act }}-V_{\text {ohmic }}-V_{\text {con }}$

The activation polarization voltage can be expressed as

$$
V_{\mathrm{act}}=\xi_{1}+\xi_{2} T+\xi_{3} T \ln \left(C_{\mathrm{O}_{2}}\right)+\xi_{4} T \ln (i)
$$

where $\xi_{1}, \xi_{2}, \xi_{3}, \xi_{4}$ are the model coefficients of experimental data on the basis of fluid dynamics, thermal and electrochemical driving force, $i$ is current density, $C_{\mathrm{O}_{2}}$ is the available oxygen concentration, and it can be expressed as

$$
C_{\mathrm{O}_{2}}=\frac{P_{\mathrm{O} 2}}{5.08 \times 10^{6} e^{\frac{-498}{T}}}
$$

The ohmic voltage drop associated with the conduction of protons through the solid electrolyte can be described as

$$
V_{\text {ohmic }}=i\left(R_{\mathrm{M}}+R_{\mathrm{C}}\right)
$$

where $R_{\mathrm{C}}$ is the contact resistance to electron flow, and $R_{\mathrm{M}}$ is the resistance to proton transfer through the membrane, which can be described as

$$
R_{M}=\frac{\rho_{M} \cdot l}{A}
$$

$$
\rho_{\mathrm{M}}=\frac{181.6\left[1+0.03\left(\frac{i}{A}\right)+0.062\left(\frac{T_{\mathrm{fc}}}{303}\right)^{2}\left(\frac{i}{A}\right)^{2.5}\right]}{\left[\psi-0.634-3\left(\frac{i}{A}\right)\right] \mathrm{e}^{\left[4.18\left(\frac{T_{\mathrm{fc}}-303}{T_{\mathrm{fc}}}\right)\right]}}
$$

where $\rho_{\mathrm{M}}$ is the membrane specific resistivity, $l$ is the membrane thickness, $A$ is the membrane active area, and $\psi$ is a specific coefficient for every type of membrane.

The voltage drop resulting from the mass transportation effects can be described by the following expression:

$$
V_{\text {con }}=-B \ln \left(1-\frac{i}{i_{\max }}\right)
$$

where $B$ is a constant depending on the type of fuel cell, $i_{\max }$ is the maximum electrical current.

For a PEMFC, the two layer separated by the membrane act as double charged layer, which can store electrical energy, and can be treated as a super capacitor. So the dynamics of the fuel cell voltage can be modeled by the addition of a capacitor $\mathrm{C}$ to the steady state model [16]. The effect of double charge layer is modelled by a capacitor $\mathrm{C}$ connected in parallel with the activation resistance.

The differential equation describes the capacitor voltage is

$$
\frac{\mathrm{d} V_{\mathrm{C}}}{\mathrm{d} t}=\frac{i}{C}-\frac{V_{\mathrm{C}}}{R_{\mathrm{con}}+R_{\mathrm{act}}}
$$

Then equation (4) can be modified to

$$
V_{\text {fc }}=E_{\text {nernst }}-V_{\mathrm{C}}-V_{\text {ohm }}
$$

Based on the above described mathematical model, a Matlab/simulink simulation model of the PEMFC can be set up [17]. Parameters used in the simulation model are shown in Table 1.

\begin{tabular}{l|l|l|l} 
Table 1: Model parameters \\
\hline Parameters & values & Parameters & values \\
\hline$\Delta G(\mathrm{~J} / \mathrm{mol})$ & 237180 & $\xi_{2}$ & $-3.12 \times 10^{-3}$ \\
$R(\mathrm{~J} / \mathrm{mol} / \mathrm{K})$ & 8.314 & $\xi_{3}$ & $-7.4 \times 10^{-5}$ \\
$\Delta S(\mathrm{~mol} . \mathrm{K})$ & 164.025 & $\xi_{4}$ & $1.87 \times 10^{-4}$ \\
$T(\mathrm{~K})$ & 353 & $T_{\mathrm{ref}}(\mathrm{K})$ & 298.15 \\
$F(\mathrm{C} / \mathrm{mol})$ & 96.487 & $l(\mathrm{um})$ & 0.0178 \\
$P_{\mathrm{H} 2}(\mathrm{~atm})$ & 2 & $A\left(\mathrm{~cm}^{2}\right)$ & 50.6 \\
$P_{\mathrm{O} 2}(\mathrm{~atm})$ & 1 & $C(\mathrm{~F})$ & 0.25 \\
$\xi_{1}$ & 0.9514 & & \\
\hline
\end{tabular}

\section{Controller Designing}

Many factors, such as temperature variations, oxygen and hydrogen pressure, load disturbance, can affect the output voltage of fuel cells. These voltage variations can be compensated by fuel pressure controlling.

The control laws of MPC are based on the following ideas: In time $k$, the optimal solution of the performance index $J$ is calculated, and the first element of the optimal control sequence $\Delta u\left(k_{\mathrm{i}}\right)$ is used as the control input. In time $k+1$, the optimal solution of the performance index $J$ is calculated repeatedly based on the new state, and this is also known as Receding Horizon Control [18], [19].

For a given discrete-time systems:

$$
\begin{aligned}
& x_{m}(k+1)=A_{m} x_{m}(k)+B_{m} u(k) \\
& y(k)=C_{m} x_{m}(k)
\end{aligned}
$$

The MPC state space model can be expressed as follows: 


$$
\begin{aligned}
& \overbrace{\left[\begin{array}{c}
\Delta x_{m}(k+1) \\
y(k+1)
\end{array}\right]}^{x(k+1)}=\overbrace{\left[\begin{array}{cc}
A_{m} & O^{T} \\
C_{m} A_{m} & 1
\end{array}\right]}^{A} \overbrace{\left[\begin{array}{c}
\Delta x_{m}(k) \\
y(k)
\end{array}\right]}^{x(k)}+\overbrace{\left[\begin{array}{c}
B_{m} \\
C_{m} B_{m}
\end{array}\right]}^{B} \Delta u(k)(13) \\
& y(k)=\overbrace{\left[\begin{array}{ll}
O_{m} & 1
\end{array}\right]\left[\begin{array}{c}
\Delta x_{m}(k) \\
y(k)
\end{array}\right]}^{C}
\end{aligned}
$$

which subjects to

$$
x_{m}(k) \in X \subset R^{n}, u(k) \in U \subset R^{m}
$$

where $x_{m}(k), u(k), y(k)$ are state, input and output vectors, respectively. Then the predicted expression of $x$ and $y$ at sampling time $k_{i}$ can be obtained as

$$
\begin{aligned}
x\left(k_{i}+1 \mid k_{i}\right)= & A x\left(k_{i}\right)+B \Delta u\left(k_{i}\right) \\
x\left(k_{i}+2 \mid k_{i}\right)= & A^{2} x\left(k_{i}\right)+A B \Delta u\left(k_{i}\right)+B \Delta u\left(k_{i}+1\right) \\
\mathrm{M} & \\
x\left(k_{i}+N_{P} \mid k_{i}\right)= & A^{N_{P}} x\left(k_{i}\right)+A^{N_{P}-1} B \Delta u\left(k_{i}\right)+B^{N_{P}-2} \Delta u\left(k_{i}+1\right) \\
& +\mathrm{L}+A^{N_{P}-N_{C}} B \Delta u\left(k_{i}+N_{C}-1\right) \\
y\left(k_{i}+N_{P} \mid k_{i}\right)= & C A^{N_{P}} x\left(k_{i}\right)+C A^{N_{P}-1} B \Delta u\left(k_{i}\right) \\
& +C B^{N_{P}-2} \Delta u\left(k_{i}+1\right)+\mathrm{L} \\
& +C A^{N_{P}-N_{C}} B \Delta u\left(k_{i}+N_{C}-1\right)
\end{aligned}
$$

If the following vectors are defined

$$
\begin{gathered}
X=\left[x\left(k_{i}+1 \mid k_{i}\right), x\left(k_{i}+2 \mid k_{i}\right),\right. \\
\left.x\left(k_{i}+3 \mid k_{i}\right), \mathrm{L} x\left(k_{i}+N_{P} \mid k_{i}\right)\right]^{T} \\
Y=\left[y\left(k_{i}+1 \mid k_{i}\right), y\left(k_{i}+2 \mid k_{i}\right),\right. \\
\left.y\left(k_{i}+3 \mid k_{i}\right), \mathrm{L} y\left(k_{i}+N_{P} \mid k_{i}\right)\right]^{T} \\
\Delta U=\left[\Delta u\left(k_{i}\right), \Delta u\left(k_{i}+1\right), \Delta u\left(k_{i}+2\right),\right. \\
\left.\mathrm{L} \Delta u\left(k_{i}+N_{C}-1\right)\right]^{T}
\end{gathered}
$$

The output expression can be denoted as

$$
Y=F X+\Phi \Delta U
$$

where

$$
\begin{aligned}
F & =\left[\begin{array}{lrrrc}
C A & C A^{2} & C A^{3} & \ldots C A^{N P}
\end{array}\right]^{T} \\
\Phi & =\left[\begin{array}{lllll}
C B & 0 & 0 & \mathrm{~L} & 0 \\
C A B & C B & 0 & \mathrm{~L} & 0 \\
C A^{2} B & C A B & C B & \mathrm{~L} & 0 \\
\mathrm{M} & & & & \\
C A^{N_{P}-1} B & C A^{N_{P}-2} B & C A^{N_{P}-3} B \mathrm{~L} & C A^{N_{P}-N_{C}} B
\end{array}\right]_{N_{P} \times N_{C}}
\end{aligned}
$$

For the current state, model predictive control is to solve the optimization problem of the form

$$
J=\left(R_{S}-Y\right)^{T}\left(R_{S}-Y\right)+\Delta U \bar{R} \Delta U
$$

which subject to the following constraints:

$$
\begin{aligned}
& U_{\text {min }} \leq U \leq U_{\max } \\
& \Delta U_{\text {min }} \leq \Delta U \leq \Delta u_{\max } \\
& Y_{\min } \leq Y \leq Y_{\max }
\end{aligned}
$$

in which $R_{S}^{T}=[1,1 \mathrm{~L}, 1] r\left(k_{i}\right), r\left(k_{i}\right)$ is the steady-state, and $\bar{R}=r_{w} I_{N_{C}} \times I_{N_{C}}, r_{w}$ is the weight. From

$$
\frac{\partial J}{\partial \Delta U}=0
$$

the optimal solution of control signals and performance indicators can be solved as

$$
\begin{aligned}
\Delta U & =\left(\Phi^{T} \Phi+\bar{R}\right)^{-1}\left(\Phi^{T} R_{S}-F x\left(k_{i}\right)\right) \\
J_{\min } & \left(R_{S}-F x\left(k_{i}\right)\right)^{T}\left(R_{S}-F x\left(k_{i}\right)\right)- \\
& \left(R_{S}-F x\left(k_{i}\right)\right)^{T} \Phi\left(\Phi^{T} \Phi+r_{w} I_{N_{C} \times N_{C}}\right)^{-1} \Phi^{T}\left(R_{S}-F x\left(k_{i}\right)\right)
\end{aligned}
$$

\section{Simulation and Results Analysis}

Select the predictive region length $N_{\mathrm{P}}=20$, the control region length $N_{C}=4, r_{w}=0.001$. The output steady-state voltage is set at $V_{\mathrm{fc}}=1 \mathrm{~V}$.

First $P_{\mathrm{O} 2}$ is chosen as a control variable. Fig. 1 shows the simulation running curves without constraints, and Fig. 2 shows the corresponding curves with constraints. The constraint conditions are $u \in[0,10], \Delta u \in[-3,3]$.

It can be seen from Fig. 1 and Fig. 2 that MPC can make the output voltage of the fuel cell follow the reference value quick and accurately.

By comparing Fig. 1 with Fig. 2, it also can be seen that, the steady-state can be reached at $0.25 \mathrm{~s}$ without constraints and $0.5 \mathrm{~s}$ with constraints. When $P_{\mathrm{O} 2}$ is chosen as the control variable, the fuel cell can reach the stable state rapidly and soon after output a constant voltage at the setting value.

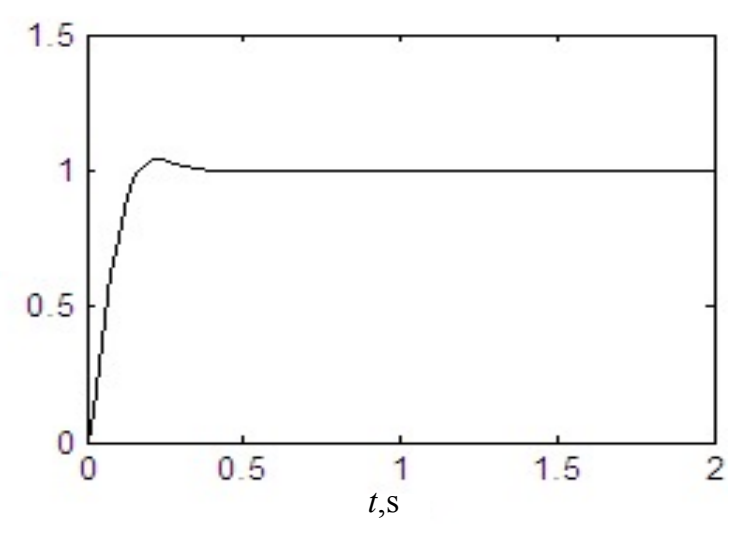




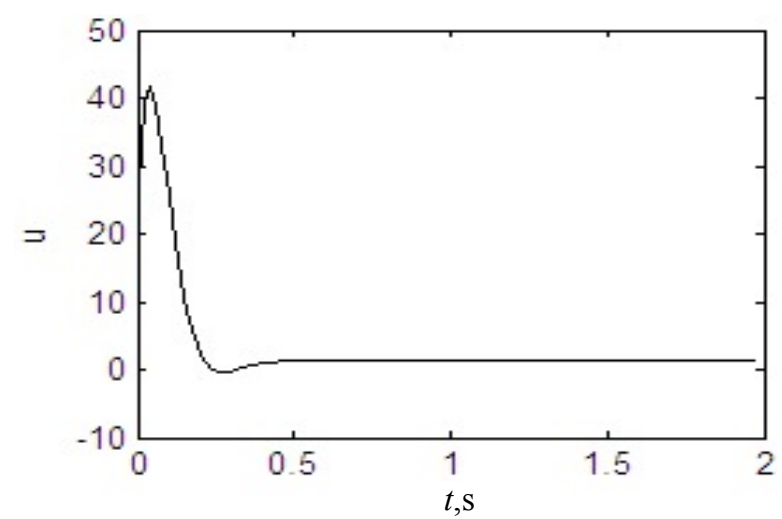

Fig.1. Simulation Results Corresponding to $P_{\mathrm{O} 2}$ as Control Variable Without Constraints
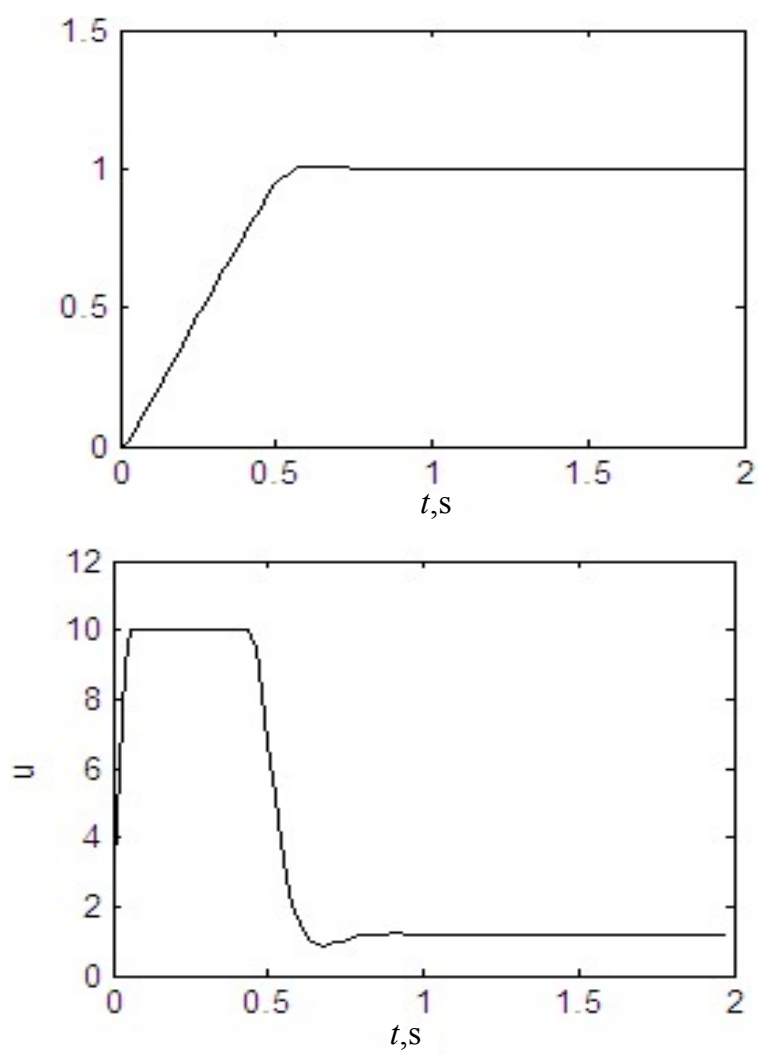

Fig. 2. Simulation Results Corresponding to $P_{\mathrm{O} 2}$ as Control Variable with Constraints

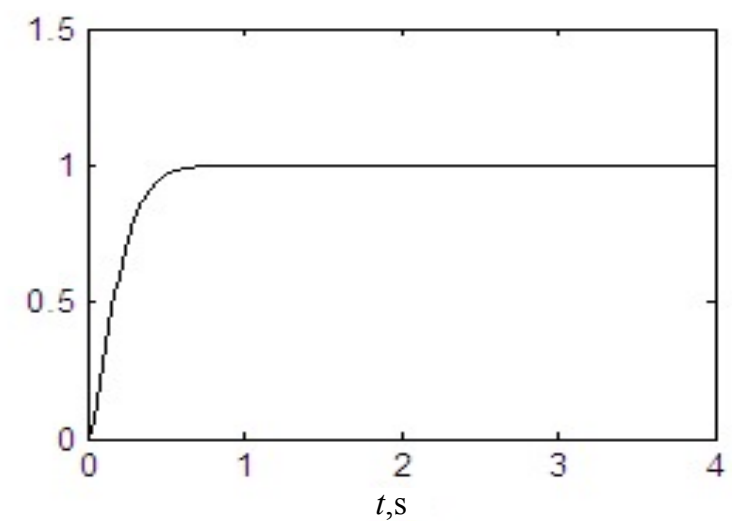

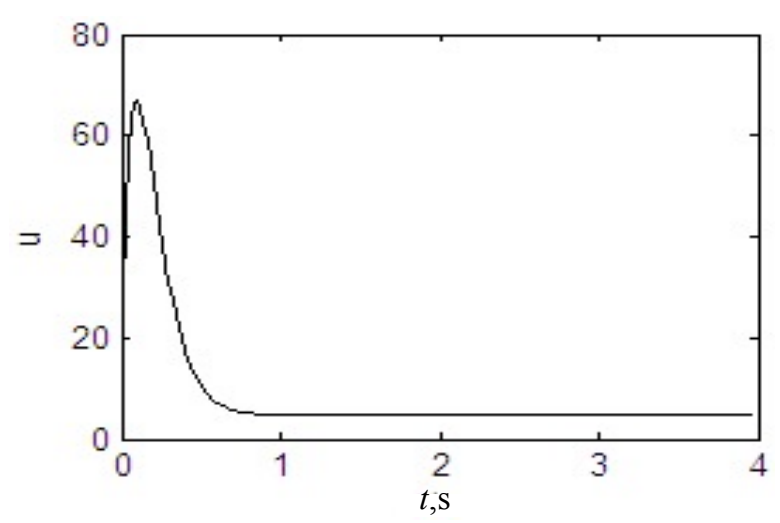

Fig. 3. Simulation Results Corresponding to $P_{\mathrm{H} 2}$ as Control Variable without Constraints

The simulation results corresponding to that $P_{\mathrm{H} 2}$ is selected as the control variable are shown in Fig. 3 to Fig. 4, in which Fig. 3 presents the results under the condition without constraints and Fig. 4 shows those with constraints. The constraints are same as what are given when $P_{\mathrm{O} 2}$ is used as the control variable.

It can be seen from Fig. 3 to Fig. 4 that the response speed is slower when $P_{\mathrm{H} 2}$ is used as control variable. On the other hand, there is an obvious discrepancy in the control effects with different constraint condition. When the MPC is designed without constraints, the response speed of the output voltage is $0.5 \mathrm{~s}$, while when the MPC is designed with constraints, the response speed is $2.8 \mathrm{~s}$.
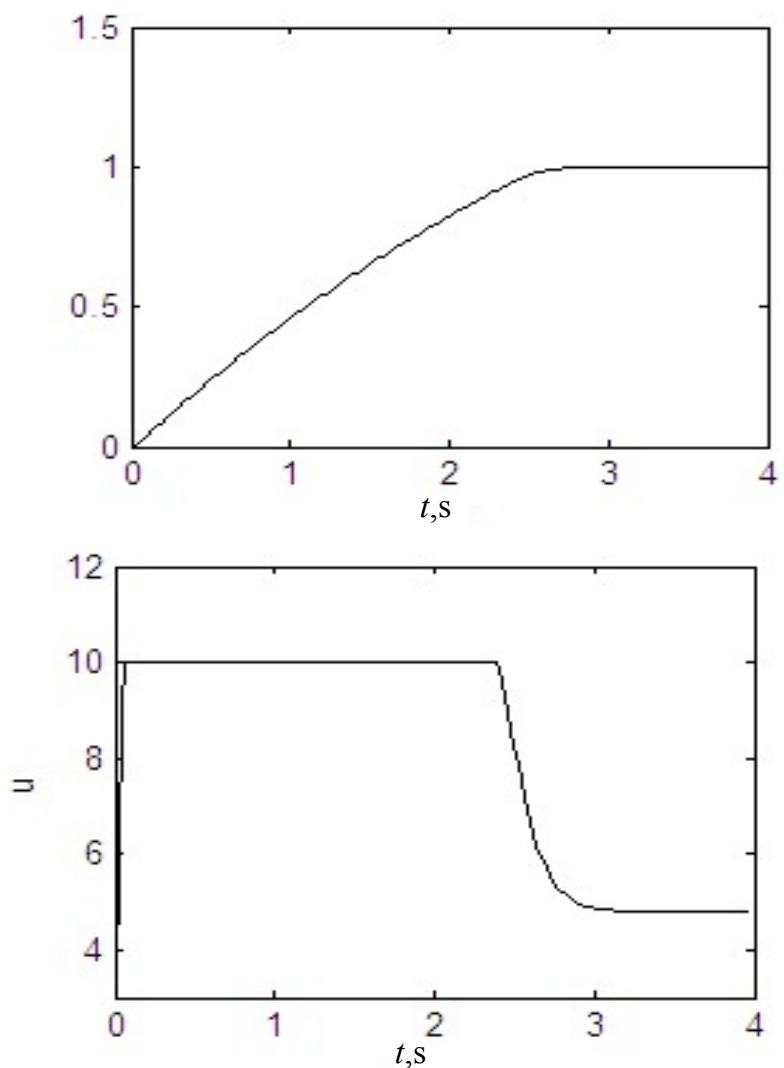

Fig. 4. Simulation Results Corresponding to $P_{\mathrm{H} 2}$ as Control Variable with Constraints

Some appearances can also be observed from Fig. 1 to Fig. 4. The control effects are basically the same when the MPC designed without constraints, either $P_{\mathrm{O} 2}$ or $P_{\mathrm{H} 2}$ as the 
control variable. While when the constraint conditions is considered in designing MPC, the control effects of these two conditions shows obvious distinctness. Therefore, using $P_{\mathrm{O} 2}$ as the control variable can get an ideal control effect, no matter whether the constraints exist.

\section{Conclusion}

By using model predictive controller, the fuel cell can not only have fast response characteristic, but also have good steady-state behavior and strong robustness. The suitable
MPC schemes can get satisfactory results in tracking a given voltage and guarantee that the fuel cells have constant voltage outputs.

\section{Acknowledgements}

This work was supported by the National Key Technology Research and Development Program of China under Grant 2012BAF09B01, and the Science and Technology Research Project of Liaoning Education Department of China under Grant L2012140.

\section{References}

1. Samosir, A. S., Sutikno, T., Yatim, A. H. M., "Dynamic evolution control for fuel cell DC-DC converter", TELKOMNIKA 9 (1), 2011, pp. 183-190.

2. Wee, J. H., "Applications of proton exchange membrane fuel cell systems", Renewable and Sustainable Energy Reviews 11 (8), 2007, pp. 1720-1738.

3. Logan, B. E., "Scaling up microbial fuel cells and other bioelectrochemical systems", Applied Microbiology and Biotechnology 85(6), 2010, pp. 1665-1671.

4. Gencoglu, M. T., Ural, Z., "Design of a PEM fuel cell system for residential application", International Journal of Hydrogen Energy 34 (12), 2009, pp. 5242-5248.

5. Pukrushpan, J., Stefanopoulou, A., Peng, H., "Control of fuel cell breathing", IEEE Control Systems 24 (2), 2004, pp. 30-46.

6. Kunusch, C., Puleston., P. F., Mayosky, M. A., Riera, J., "Sliding mode strategy for PEM fuel cells stacks breathing control using a super-twisting algorithm", IEEE Transactions on Control Systems Technology 17 (1), 2009, pp. 167-174.

7. Kaytakoglu, S., Akyalm, L., "Optimization of parametric performance of a PEMFC", International Journal of Hydrogen Energy 32 (17), 2007, pp. 4418-4423.

8. Ashoori, A., Moshiri, B., Sedigh, A. K., Bakhtiari, M. R., "Optimal control of a nonlinear fed-batch fermentation process using model predictive approach", Journal of Process Control 19 (7), 2009, pp. 1162-1173.

9. Dominguez, L. F., Pistikopoulos, E. N., "Recent advances in explicit multiparametric nonlinear model predictive control", Industrial \& Engineering Chemistry Research 50 (2), 2011, pp. 609-619.

10. Holkar, K. S., Waghmare, L. M., "An overview of model predictive control", International Journal of Control and Automation 3 (4), 2010, pp. 47-63.
11. Qin, S. J., Badgwell, T. A.. "A survey of industrial model predictive control technology", Control engineering practice 11 (7), 2003, pp. 733-764.

12. Carnes, B., Djilal, N., "Systematic parameter estimation for PEM fuel cell models", Journal of Power Sources 144 (1), 2005, pp. 8393.

13. Moreira, M. V., Silva, G. E., "A practical model for evaluating the performance of proton exchange membrane fuel cells", Renewable Energy 34 (7), 2009, pp. 1734-1741.

14. Rezazadeh, A., Sedighizadeh, M., Karimi, M., "Proton exchange membrane fuel cell control using a predictive control based on neural network", International Journal of Computer and Electrical Engineering 2 (1), 2010, 81-85

15. Youssef M. E., Nadi K. E., Khalil M. H., Lumped model for proton exchange membrane fuel cell (PEMFC). International Journal of Electrochemical Science 5, 2010, pp. 267-277.

16. Esmaeili, S., Shafiee, M., "Simulation of dynamic response of small wind-photovoltaic-fuel cell hybrid energy system", Smart Grid and Renewable Energy 3 (3), 2012, pp. 194-203.

17. Fan, L. P., "Simulation study on the influence factors of generated output of proton exchange membrane fuel cell", Applied Mechanics and Materials 121-126, 2012, pp. 2887-2891.

18. Hedjar, R.., "Application of nonlinear rescaling method to model predictive control", International Journal of Control, Automation, and Systems 8 (4), 2010, pp. 762-768.

19. Thammano, A., Ruxpakawong, P., "Nonlinear dynamic system identification using recurrent neural network with multi-segment piecewise-linear connection weight", Memetic Computing 2 (4) 2010, pp. 273-282. 